UCRL-ID-134164

\title{
Two Wire Wakefield Measurements of the DARHT Accelerator Cell
}

Scott D. Nelson

Michael Vella

May 1999

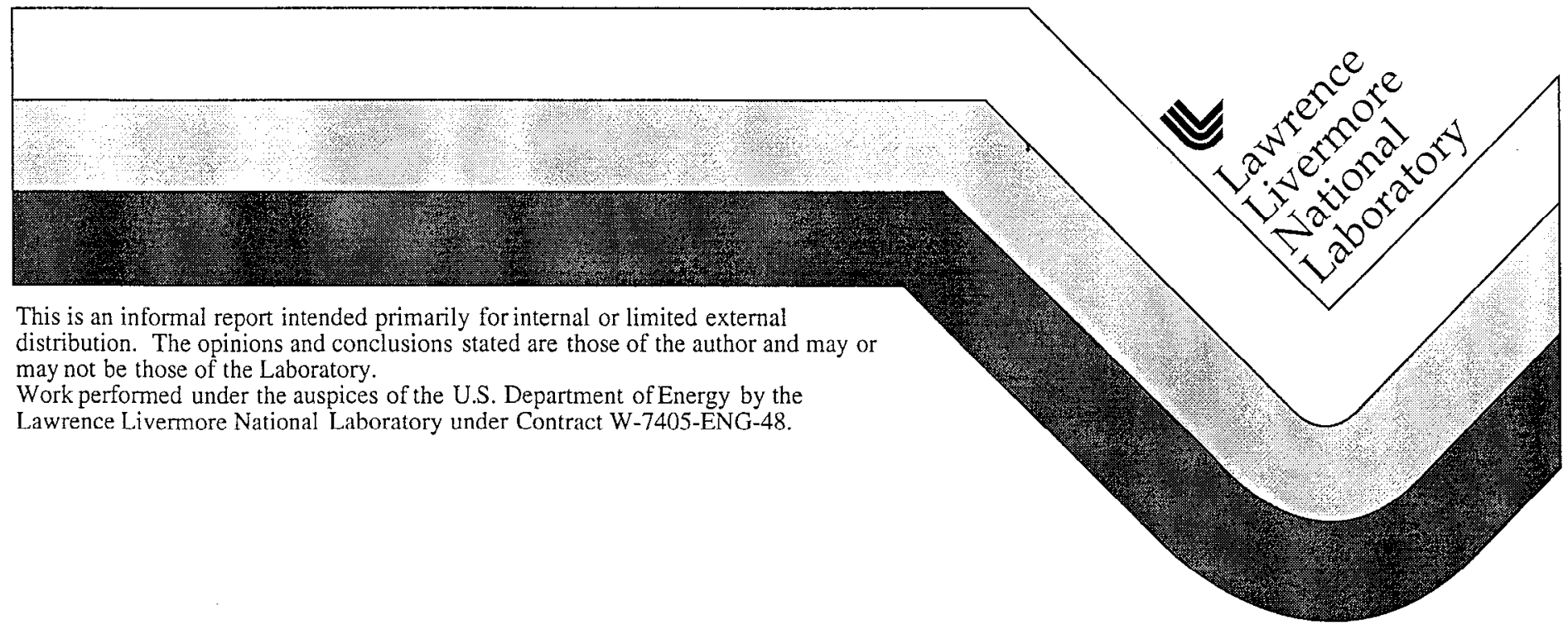




\section{DISCLAIMER}

This document was prepared as an account of work sponsored by an agency of the United States Government. Neither the United States Government nor the University of California nor any of their employees, makes any warranty, express or implied, or assumes any legal liability or responsibility for the accuracy, completeness, or usefulness of any information, apparatus, product, or process disclosed, or represents that its use would not infringe privately owned rights. Reference herein to any specific commercial product, process, or service by trade name, trademark, manufacturer, or otherwise, does not necessarily constitute or imply its endorsement, recommendation, or favoring by the United States Government or the University of California. The views and opinions of authors expressed herein do not necessarily state or reflect those of the United States Government or the University of California, and shall not be used for advertising or product endorsement purposes.

This report has been reproduced directly from the best available copy.

Available to DOE and DOE contractors from the Office of Scientific and Technical Information

P.O. Box 62, Oak Ridge, TN 37831

Prices available from (615) 576-8401, FTS 626-8401

Available to the public from the

National Technical Information Service

U.S. Department of Commerce

5285 Port Royal Rd.,

Springfield, VA 22161 


\title{
TWO WIRE WAKEFIELD MEASUREMENTS OF THE DARHT ACCELERATOR CELL
}

\author{
Scott D. Nelson, LLNL and Michael Vella, LBL
}

\section{Overview}

One of the characteristics specifying the performance of an accelerator cell as it relates to the electron beam, is the Wakefield impedance [1]. The real part of the transverse wakefield impedance relates to offsets of the beam as it travels through the accelerator cell. To verify that the cell operates as expected, and that simulations and design predictions of the cell are within acceptable parameters (before building more cells) it is desirable to measure the wakefield impedance using the traditional two-wire technique $[2,3,4]$. This technique benefits from its reproducibility and physical simplicity but is complicated by the need to fabricate a test fixture. But once the fixture is fabricated, it is simple to measure any number of accelerator cells. The following is a description of the two-wire measurement technique as performed at Lawrence Berkeley Lab (LBL) on a prototype DARHT accelerator cell.

\section{INTRODUCTION}

The frequency band of interest for the wakefield impedance measurements of the accelerator typically go from low frequencies (DC) to the cut-off point for the high order modes. As such, the two wire technique forms a balanced TEM transmission line which propagates the RF energy through the cell. A series of test fixtures were fabricated to serve as the reference for the measurement allowing the effects of the two-wires, beam-pipe, end flanges, and balun, to be unfolded from the measurement and removed. Most of the effort in performing the twowire technique is in the fabrication of the fixture. Other issues that must be addressed during the execution of the technique include the coupling between the balun and the cell itself and the repeatability of the mechanical process of attaching these fixtures to the cell. Once the RF measurements are performed on the two-wire fixture and on the cell, then it is a simple matter to unfold the wakefield impedance.

\section{TWO WIRE FIXTURE}

LBL fabricated the two-wire reference fixture used in the measurements using tight tolerances and incorporated several features to aid in the mechanical repeatability of the measurement. Figure 1 shows the components which comprise the reference fixture. The dimensions of the various structures are summarized in Table 1.
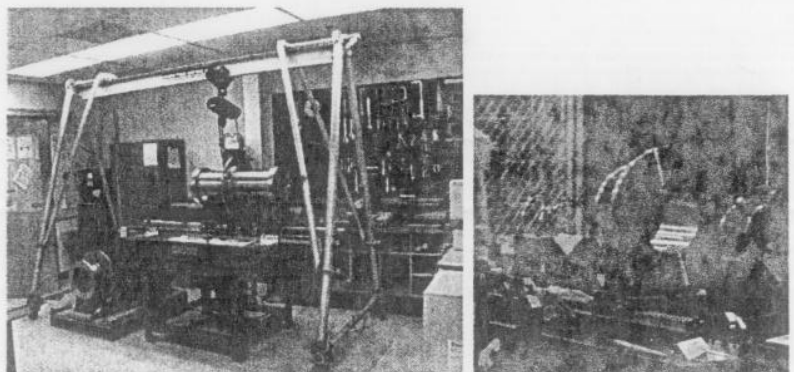

Figure 1. The two-wire test fixture being assembled in the LBL facility. The photo on the left shows the two end pipes assembled on the V-blocks on rails. The delay and through pipes are on the floor on the pallet. The photo on the right shows the delay (the two end pipes have been removed from their V-blocks and are attached to the cell). Numerous bolts and alignment pins allow the orientations of the pieces to be mechanically reassembled.

\begin{tabular}{|c|c|}
\hline pipe diameter & $25.4 \mathrm{~cm}$ \\
\hline wire diameter & $5.4 \mathrm{~mm}$ \\
\hline wire spacing & $12.00 \mathrm{~cm}$ \\
\hline spacer plate thickness & $0.25^{\prime \prime}$ \\
\hline shorting plate thickness & $0.25^{\prime \prime}$ \\
\hline delay pipe length & $\sim 21.8 \mathrm{~cm}$ \\
\hline through pipe length & $\sim 73.0 \mathrm{~cm}$ \\
\hline end pipe lengths & $\sim 37.3 \mathrm{~cm}$ \\
\hline
\end{tabular}

The impedance of the opposite polarity two-wire transmission line comes from [5] yielding $400.5 \Omega$

$$
Z_{0}=\frac{1}{\pi} \sqrt{\frac{\mu_{0}}{\varepsilon}}\left[\ln \left[2 p \frac{1-q^{2}}{1+q^{2}}\right]-\frac{1+4 p^{2}}{16 p^{4}}\left(1-4 q^{2}\right)\right]
$$

and is fed by the balun thus producing a $180^{\circ}$ phase change between the two wires. Where $p=s / d, q=s / D$, $s=$ wire separation, $d=$ wire diameter, and $D=$ pipe diameter.

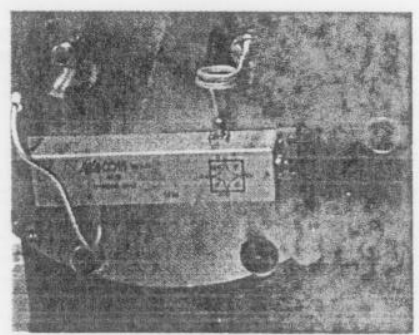

Figure 2. The balun used in the system drives the two wires $180^{\circ}$ out of phase. The input coaxial port attaches on the left (port A) and a matching $50 \Omega$ termination is placed on the right (port B). Ports $C$ and $D$ attach to the $N$ connectors. 
The balun that was used to go from coax to twin line was rated from $2 \mathrm{MHz}$ to $2000 \mathrm{MHz}$. The configuration of the balun in the rest of the system is shown in Figure 3.

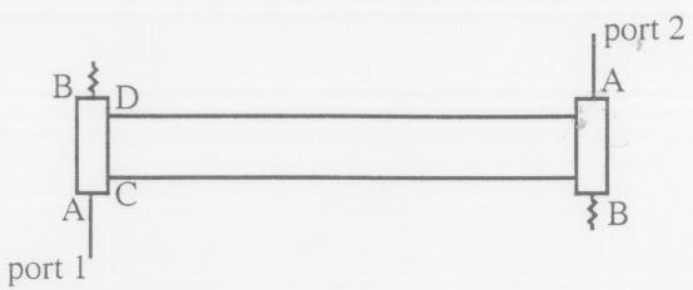

Figure 3. the baluns were connected to the cell as shown. Notice how the baluns are reversed so that the $180^{\circ}$ phase change is maintained consistently between the wires and the coaxial cables feeding ports 1 and 2 . Ports 1 and 2 are as referenced through out this report (e.g. $s_{21}$ and $s_{11}$ )

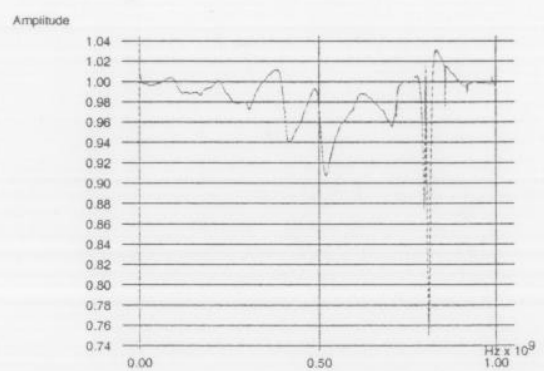

Figure 4. a fixture-calibrated raw-data scan of the cell shows a sharp physical resonance of the system at about $800 \mathrm{MHz}$ (797 and $809 \mathrm{MHz}$.)

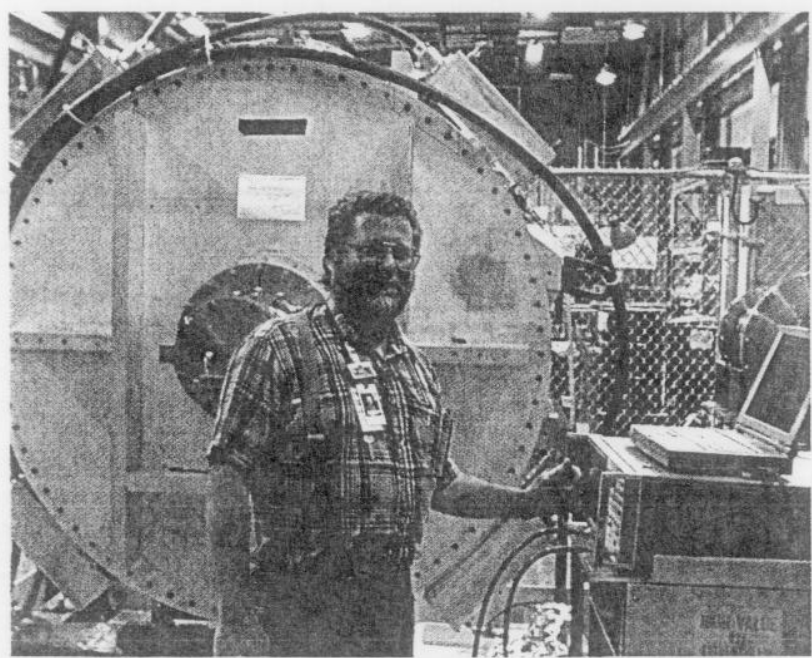

Figure 5 . the test setup at LBL in building 77A for measuring the 6 -foot diameter, 16,000 pound, DARHT cell. This is the same location that the pulsed power testing is being performed. The microwave instrumentation is on the right side of the photo with cables connected to the twin wires running through the cell. The large black cell drive cables are connected to a dummy $50 \Omega$ load for this test since the cell is not pulsed during microwave tests! Jim Dunlap (LLNL) is pictured in the foreground while making measurement.
dB

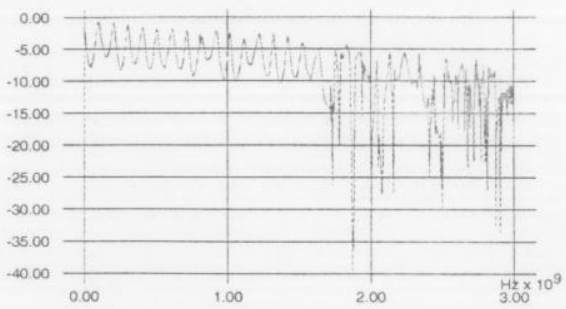

Figure 6. raw data frequency sweep of the cell from $300 \mathrm{kHz}$ to $3 \mathrm{GHz}$ reveals resonances of the test stand at the higher frequencies. Prominent higher order modes start appearing at $1.73,1.78,1.87 \mathrm{GHz}$.

Due to the physical construction of the test fixture, there are many resonances in the higher frequency bands. Since the balun was only rated to $2 \mathrm{GHz}$, data above $2 \mathrm{GHz}$ is not a reliable indication of the performance of the cell.

\section{MEASUREMENT ACCURACY}

There are several sources of error as part of performing the twin-wire measurements. The accuracy of the reference fixture, the agreement between the physical structure of the cell and the reference fixture, the mechanical stability of the cell, the electrical repeatability of the measurement, and the wear on the cables and connectors.

To determine electrical repeatability, two measurements were performed on different days looking at the performance of the cell. These two results agreed to with in $0.11 \%$ and $0.13 \%$ respectively.
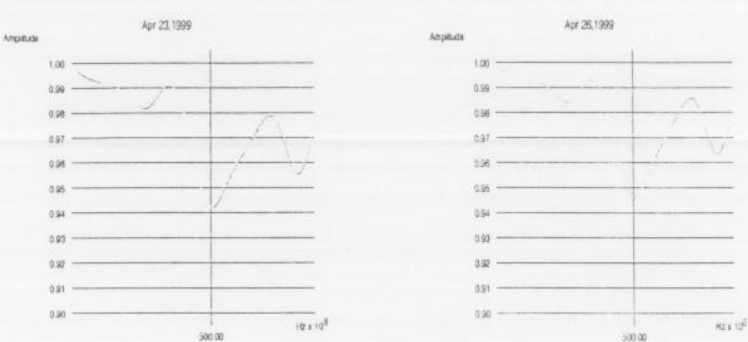

Figure 7 . electrical repeatability of the measurement was $0.11 \%$ and $0.13 \%$ on the days that it was specifically measured. The differences between days are mechanical differences in the cell (see Figure 8).

Mechanical repeatability issues were compounded by several observations made about the cell: flange-to-flange length changed by $2 \mathrm{~mm}$ during the move from building 56 to building $77 \mathrm{~A}$, thus necessitating the use of shim spacers. Additional length changes in the cell were observed after several days of having been under vacuum and pulsed. At this point, it is not known if this is just a settling issue or if this dimensional variation process will continue. 


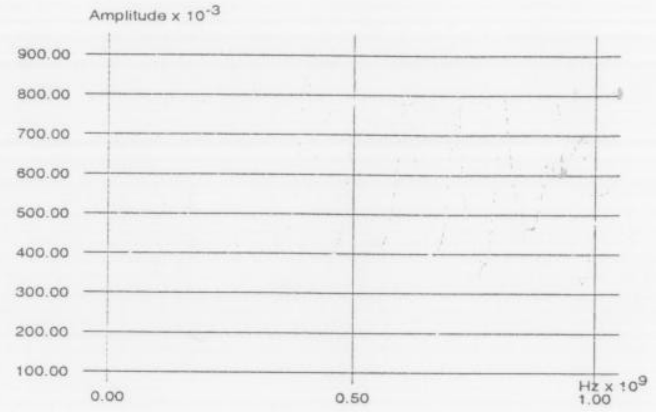

Figure 8 . to confirm the differences in the measurements from Figure 7 were mechanical, the reference fixture was measured on the same two days (April 23 and 26) and the results are shown here. There are two plots shown in the above graph that are on top of each other. The error between the two is $0.1-0.2 \%$ across the band and agrees with the error terms described in Figure 7 .

Many of the mechanical repeatability issues in regards to the fixture were addressed on the first day of testing by the LBL Mechanical Technicians. The addition of alignment pins in the cell allowed for easier transitions from the granite table top (where the reference fixture rolls on rails) over to the cell. Critical alignment was performed on the first day using optical alignment techniques. Then, pins were installed in the cell with the addition of reference blocks which were welded to the cell. This greatly facilitated the timely testing of the cell since a complete data set must be acquired in one day so that the network analyzer calibrations remain accurate.

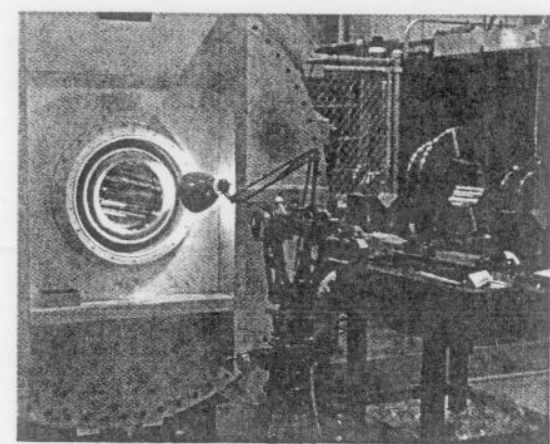

Figure 9. the LBL optical alignment procedure aligned the input and output pipes with respect to the cell. Later, reference blocks and pins were welded in place on the cell to allow the alignments to be reproduced. Also visible in this photo are the cell insulator (dark brown ring) and the radiused gap edge.

Since the electrical accuracy terms shown in Figures 7 and 8 are small, the differences between the two days' measurements are due to differences in the cell mechanical alignments or dimensions. These include alignment errors and beampipe offset errors introduced via the jacking screws which position the beampipe in the accelerator cell.

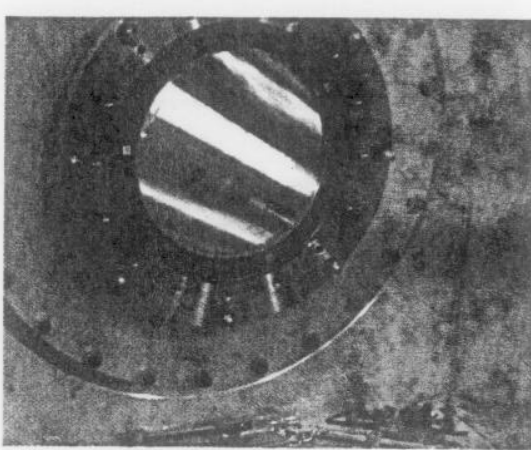

Figure 10. six jacking screws were used to keep the beampipe round and to align it with respect to the cell. The inner surface of the beampipe was machined for interior roundness (notice the changes in the beampipe wall thickness.)

Other than the cell length expansions, there was also a beampipe misalignment that occurred. This alignment error was on the order of 30 mils and caused a noticeable change in the wakefield impedance data (April 23, 1999). Other than the inclusion of the jacking screws used to position the beampipe, the remainder of the system was mechanically : ery reproducible.

\section{FIXTURE MEASUREMENTS}

The reference fixture (Figure 1) is used to calibrate the network analyzer. Then, by moving the test setup over to the cell, the differences between the cell and the straight pipe of the reference fixture are determined and allows for the greatest amount of accuracy. The measurement of the fixture involves 4 steps:

1. measurement of the through

2. measurement of the delay

3. measurement of the short

4. measurement of the spacer plate

These calibration steps are performed after the network analyzer itself is calibration using a standard calibration kit. This initial step is performed as a check to make sure that the system itself is operating correctly and than sufficient time has elapsed for the equipment to warm up and stabilize. Then the TSD standards are used to establish the references for the experiment. The spacer plate mentioned above (and in Table 1) is just a plate that is the same thickness as the shorting plate, but with a pipe-diameter sized hole in it.

Figure 11 starts the step-by-step process beginning with the calibration procedure for the network analyzer. This is just the response for the test set and the cable and has a typical lossy response at higher frequencies. The calibration procedure then removes these effects from the system and establishes that as the reference measurement. 


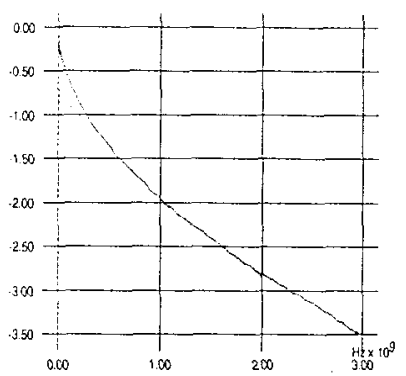

Figure 11. for reference, the $s_{21}$ measurement on the cables is acquired as the first step in the procedure. Then, the cable and network analyzer effects are calibrated out of the system. High bandwidth cables with SMA connectors were used for the measurements. Shown here are the effects of the cables and rietwork analyzer from $300 \mathrm{kHz}$ to $3 \mathrm{GHz}$.

The initial calibration procedure removes these effects.

Figure 12 shows the reference fixture's reflection and transmission coefficients. Since the pipe has flat panels on each end, it looks like a resonant cavity. After the pipe calibration procedure, these effects are also removed.
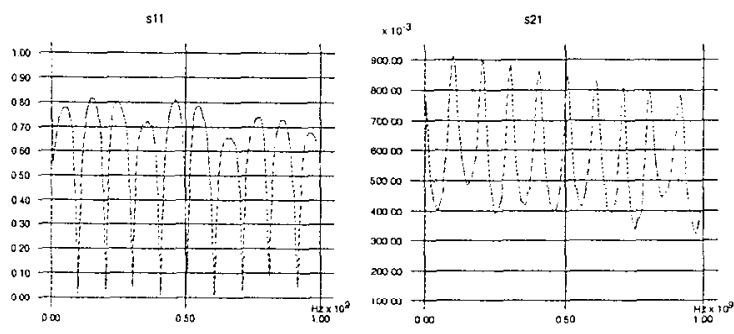

Figure 12. $s_{11}$ and $s_{21}$ for the reference fixture are measured to insure that the system is aligned and operating properly before calibration using the standards.

\section{WAKEFIELD IMPEDANCES}

Calculation of the wakefield impedance for the cell involves several steps. After the fixture calibration standards have been established, it is necessary to measure the cell (see Figure 4 for a typical raw spectra). But at this point, the system still contains resonances representing the closed structure of a resonant cavity. If the network analyzer does not have a time gating capability, then you must perform that operation manually. For reference purposes, the steps are as follows: (1) spectrally pad the data with an appropriate window. For these experiments, we chose to extend the window to $10 \mathrm{GHz}$. (2) inverse Fourier transform the data to get into the time domain. (3) temporarily crop the data to extract only the initial waveform. (4) transform back into frequency space. These steps are illustrated in Figure 13.
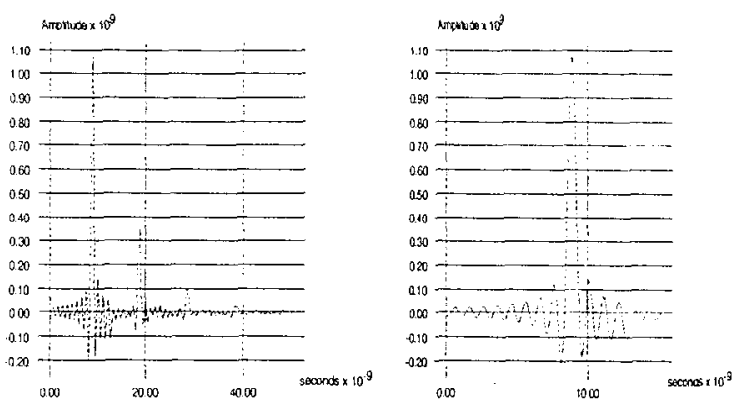

Figure 13. for network analyzers not having a time gating capability, it is necessary to manually extract the initial synthesized waveform [2].

The resulting wakefield impedance is obtained in the frequency domain by applying the calibration function [3]

$$
\Re\left\{Z_{\perp}\right\}=\frac{2 Z_{0} c}{s^{2}} \frac{1}{2 \pi f} \frac{r-r^{2}+x^{2}}{r^{2}+x^{2}}
$$

where $\mathrm{Z}_{0}$ is the impedance of the shielded two-wire line (400.5 $\Omega$ ), $s$ is the wire-to-wire separation in meters, $f$ is the frequency in $\mathrm{Hz}, r$ is the real part of the resulting $s_{21}$ parameter after converting the cropped time domain waveform back into the frequency domain, and $x$ is the imaginary part of the resulting $s_{21}$ parameter. The units of (2) are $\Omega / \mathrm{m}$.

Thus, the resulting transverse resistance can be calculated. Based on the mechanical changes observed on the various days, the results for April 15 and April 26, 1999 are shown and agree to with in $25 \Omega / \mathrm{m}$. The results from April 23 had a $50 \Omega / \mathrm{m}$ deviance due to an obvious mechanical alignment problem of the beampipe which could not be corrected before the end of the day's testing.

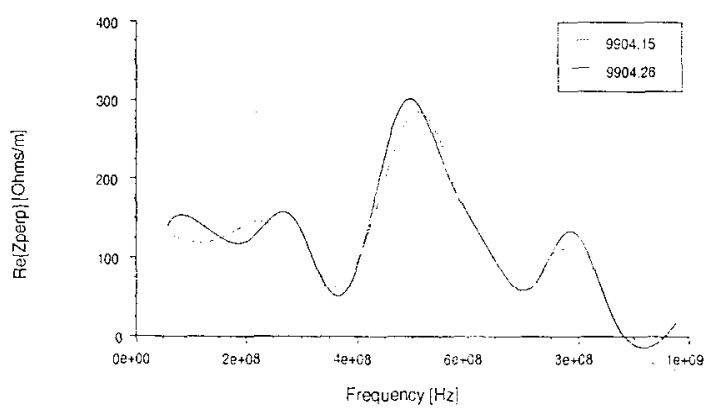

Figure 14. the transverse wakefield resistance for the DARHT prototype cell (a.k.a. Cell \#2) is shown for April 15 and April 26, 1999 


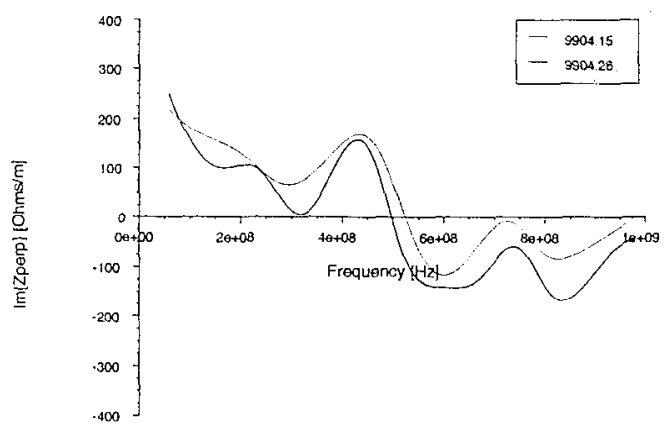

Figure 15. the transverse wakefield reactance for the DARHT prototype cell (a.k.a. Cell \#2) is shown for April 15 and April 26, 1999.

Similarily, the transverse wakefield reactance is obtained from

$$
\mathfrak{I}\left\{Z_{\perp}\right\}=\frac{2 Z_{0} c}{s^{2}} \frac{1}{2 \pi f} \frac{x}{r^{2}+x^{2}}
$$

\section{CONCLUSIONS}

The wakefield impedance of the cell has been confirmed to be quite low and the performance of the cell over most of the band is excellent. However, the resonance at $800 \mathrm{MIIz}$ is suspicious and should be identified before proceeding. It has not been determined yet if this is due to the test setup (twin wires and end pipes) interacting with the cell or if it is a characteristic of the cell itself. The fact that this resonance is similar to the longitudinal resonance of the structure leads the authors to believe that it is characteristic of the test setup. IIowever, this effect is only seen when measuring the cell and at that point the cell radius is dimensionally on the same order.

One recommendation for those performing twin-wire measurements in the future would be the inclusion of a standard pillbox as part of the reference set of fixtures. Ordinarily, the results of the twin-wire measurement are compared against model results [6] to confirm the absolute calibration. But in this case, the model is awaiting experimental data for the ferrite. So a standard pillbox cavity could have been used with the twin-wire technique to confirm the absolute calibration. In the interim, the Briggs/ Birx technique was used as the quantitative verification and those results agree to within a $30 \%$ error bar with the twin wire technique.

\section{ACKNOWLEDGMENTS}

The authors would like to thank the LBL Mechanical designers and fabricators for their efforts in supporting this activity by fabricating the reference fixture which was instrumental in these measurements. To Jim Dunlap, of LLNL, for his work in performing these measurements, to Carlos Avalle for his advice on the methodology, and to Tim Houck for his design work on the DARHT cell. Thanks also go to the Mechanical team in the lab for their expertise and efficiency in modifying the cell to allow for these measurements to take place. This work was performed under the auspices of the U.S. Department of Energy by the Lawrence Livermore National Laboratory under contract No. W-7405-Eng-48.

\section{REFERENCES}

[1] J. DeFord, et. al., "Development and Applications of Dispersive Soft Ferrite Models for Time-Domain Simulation", LLNL, 1992.

[2] L. W. Walling, D. E. McMurry, D. V. Neuffer, H. A. Thiessen "Transmission-Line Impedance Measurements for an Advanced Hadron Facility," Nuclear Instruments and Methods in Physics Research, A281 (1989) 433-447.

[3] S. Eylon, E. Henestroza, J.-S. Kim, T. L. Houck, G. A. Westenskow, S. S. Yu, "Longitudinal Impedance Measurement of an RK-TBA Induction Accelerating Gap," 1997 Particle Accelerator Conference, Vancouver, B. C. Canada, May 12-16, 1997, LLNL UCRL-JC127272.

[4] L. W. Walling, P. Allison, M. Burns, D. J. Liska, D. E. McMurry, A H. Shapiro, "Transverse Impedance Measurements of Prototype Cavities for a Dual-Axis Radiographic Hydrotest (DARHT) Facility," Los Alamos National Laboratory, August 199 !.

[5] R. E. Collin, "Foundations for Microwave Engineering," Section 3.3, McGraw-Hill Book Company, New York, 1966, ISBN 07$011801-9$.

[6] T. L. Houck, Y-J Chen, C. C. Shang, L. L. Reginato, S. S. Yu, "Physics Design of the DARHT $2^{\text {nd }}$ Axis Accelerator Cell," $19^{\text {th }}$ International Linear Accelerator Conference, Chicago, lllinois, August 2328,1998 , LLNL UCRL-JC- 130424 